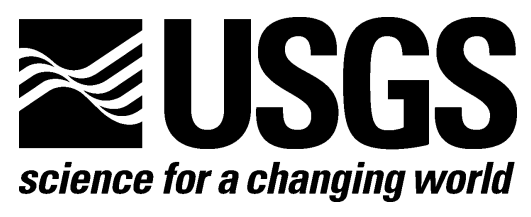

\title{
Reserve Growth of Alberta Oil Pools
}

By Mahendra K. Verma ${ }^{1}$ and Troy Cook $^{1}$

Open-File Report 2008-1194

U.S. Department of the Interior U.S. Geological Survey

${ }^{1}$ USGS, Central Region, P.O. Box 25046, MS 939, Denver, CO 80225 


\section{U.S. Department of the Interior DIRK KEMPTHORNE, Secretary}

\section{U.S. Geological Survey \\ Mark D. Myers, Director}

U.S. Geological Survey, Reston, Virginia: 2008

For product and ordering information:

World Wide Web: http://www.usgs.gov/pubprod

Telephone: 1-888-ASK-USGS

For more information on the USGS - the Federal source for science about the Earth, its natural and living resources, natural hazards, and the environment:

World Wide Web: http://www.usgs.gov

Telephone: 1-888-ASK-USGS

Suggested citation:

Verma, M.K., and Cook, Troy, 2008, Reserve growth of Alberta oil pools: U.S. Geological Survey Open-File Report 2008-1194, 10 p.

Any use of trade, product, or firm names is for descriptive purposes only and does not imply endorsement by the U.S. Government.

Although this report is in the public domain, permission must be secured from the individual copyright owners to reproduce any copyrighted material contained within this report. 


\section{Introduction}

This Open-File Report is based on a presentation delivered at the Fourth U.S. Geological Survey Workshop on Reserve Growth on March 10-11, 2008. It summarizes the results of a study of reserve growth of oil pools in Alberta Province, Canada. The study is part of a larger effort involving similar studies of fields in other important petroleum provinces around the world, with the overall objective of gaining a better understanding of reserve growth in fields with different geologic/reservoir parameters and different operating environments.

The goals of the study were to:

1. Evaluate historical oil reserve data and assess reserve growth.

2. Develop reserve growth models/functions to help forecast hydrocarbon volumes.

3. Study reserve growth sensitivity to various parameters - for example, pool size, porosity, oil gravity, and lithology.

4. Compare reserve growth in oil pools/fields of Alberta provinces with those from other large petroleum provinces.

\section{Data Management}

The geologic/reservoir/production data for Alberta pools were obtained from the Alberta Energy and Utilities Board, partly on microfiche (from 1960 through 1977) and partly in digital format (1978 through 2005), which resulted in an extensive database with more than 12,000 oil pools and 46 years of historical record. The data were checked for accuracy and the continuity of pools was verified based on production histories, as the names of some pools were changed over time. After initial data screening/editing, only those pools producing from years of discovery through 2000 and beyond were included in the study. For the pools that stopped producing in some years after 2000, the recoverable hydrocarbon volumes of their last reporting year (for example, in 2003) were repeated for the remaining years through 2005. Similarly, if records of recoverable hydrocarbon volumes for pools discovered prior to 1960 were missing for any of the years between 1960 and 1964, the reported post-1960 volumes were extended backward to 1960. In this manner, about 9,100 oil pools were selected for study. 


\section{Methodology}

Discovery tables were prepared from the assembled database, and the Modified Arrington method (Verma, 2005) was used to estimate cumulative reserve growth values. The cumulative reserve growth data were plotted against the years since discovery, and were regressed using a power function to develop reserve growth functions.

\section{Analysis and Discussions}

The total recoverable oil volume of the Alberta Province increased from 4.48 billion barrels in 1960 to more than 17.01 billion barrels in 2005 (fig. 1). This included both new discoveries as well as reserve growth. The reserve growth in Alberta oil pools is about 2.9-fold over a 50-yr period (fig. 2). Pool size distribution showed 125,000 barrels as the median/mode (fig. 3). Reserve growth was then evaluated for pools with recoverable oil volumes both larger and smaller than 125,000 barrels; results show most growth was in the larger pools, which make up the bulk of the total volume (fig. 4).

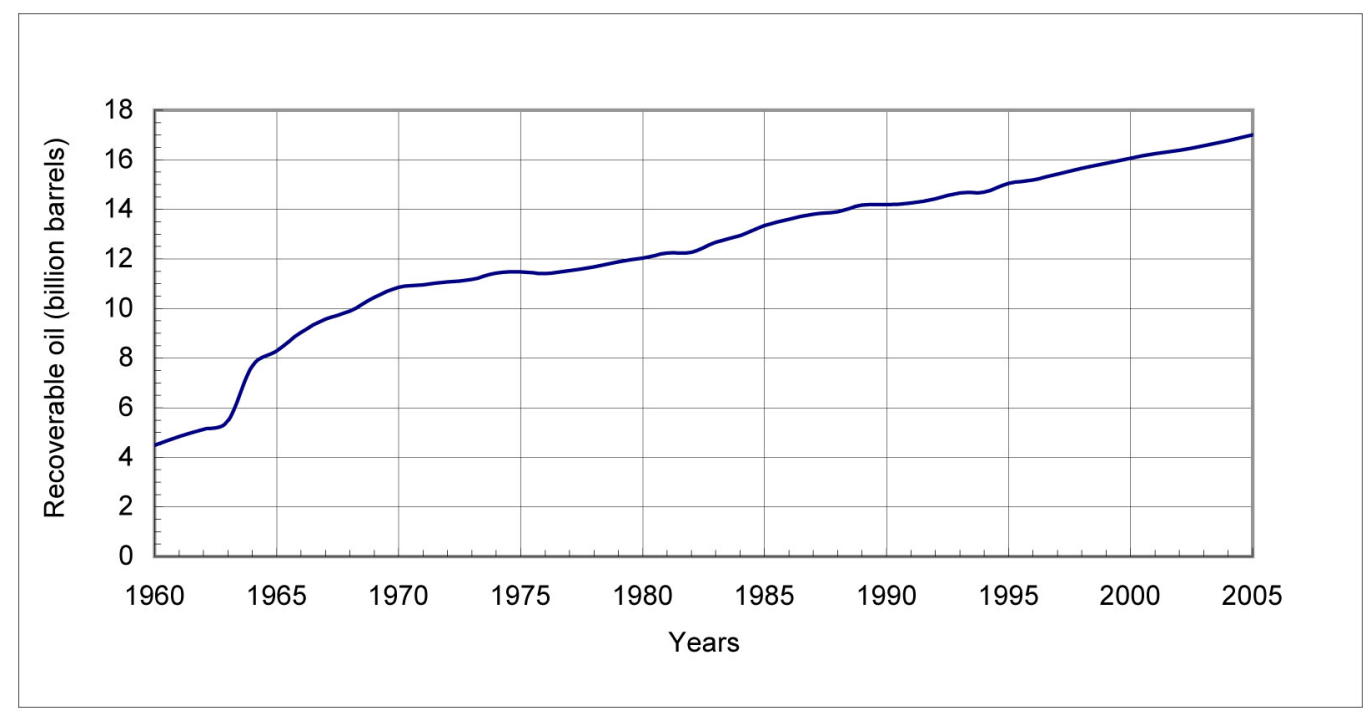

Figure 1. Increase in total recoverable oil volume, excluding tar sands, in the Alberta Province over the historical period from 1960 to 2005. This is the total volume of oil from new discoveries and reserve growth. 


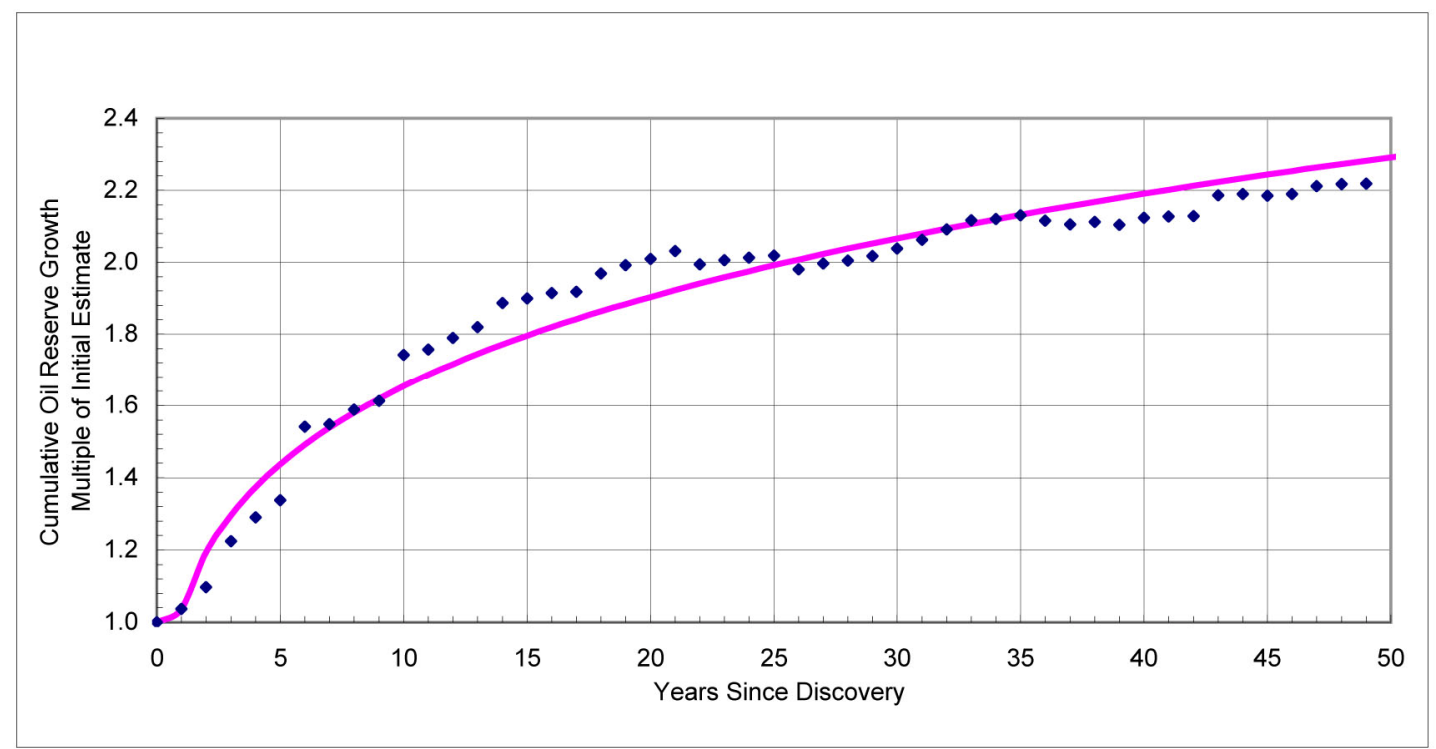

Figure 2. Cumulative reserve growth factors since discovery year for Alberta oil pools (blue diamonds). Data are plotted, and are regressed using Power function (purple curve) to help develop an equation for predicting reserve growth.

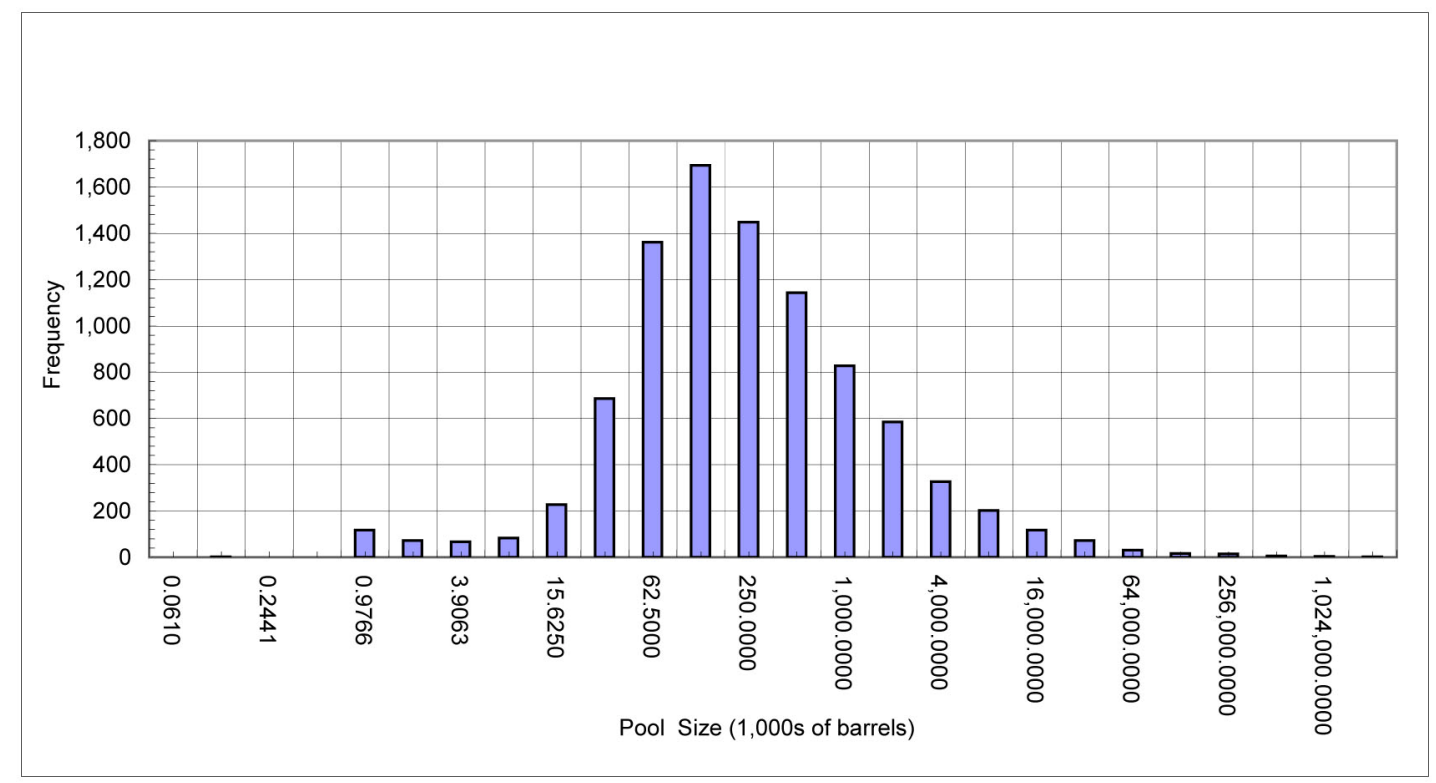

Figure 3. Size distribution of oil pools in Alberta Province, Canada. Graph shows 125,000 barrels as the median/mode of pool sizes. 


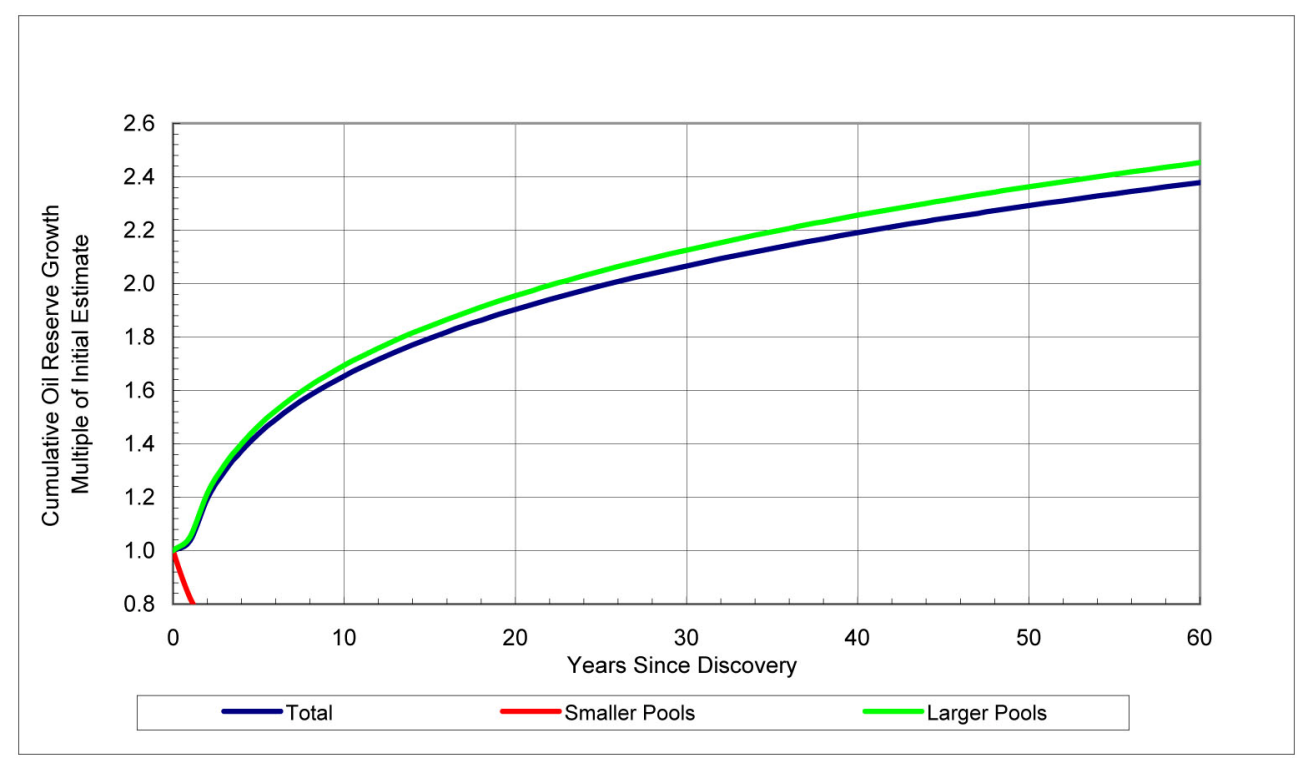

Figure 4. Reserve growth for Alberta oil pools. It is evident that most of the growth has occurred in the larger pools - those containing more than 125,000 barrels of total recoverable oil volumes, as opposed to those having less than 125,000 barrels.

To check the sensitivity to oil gravity, pools were grouped in three categories based on gravity - heavy oil with gravity less than $20^{\circ} \mathrm{API}$; medium oil with gravity between 20 and $30^{\circ} \mathrm{API}$; and light oil with gravity greater $30^{\circ} \mathrm{API}$. The cumulative reserve growth values were calculated and plotted for the relative reserve growth in these three types of oil pools, as shown in figure 5 . The results indicated that, although the pools with heavy oil had a smaller share (3.8 percent) of the total recoverable oil, they showed a significantly larger growth compared to the pools with medium and light oils. The pools with light oil accounted for most of the total oil volume ( 85.2 percent) and therefore mirrored the overall pool growth. 


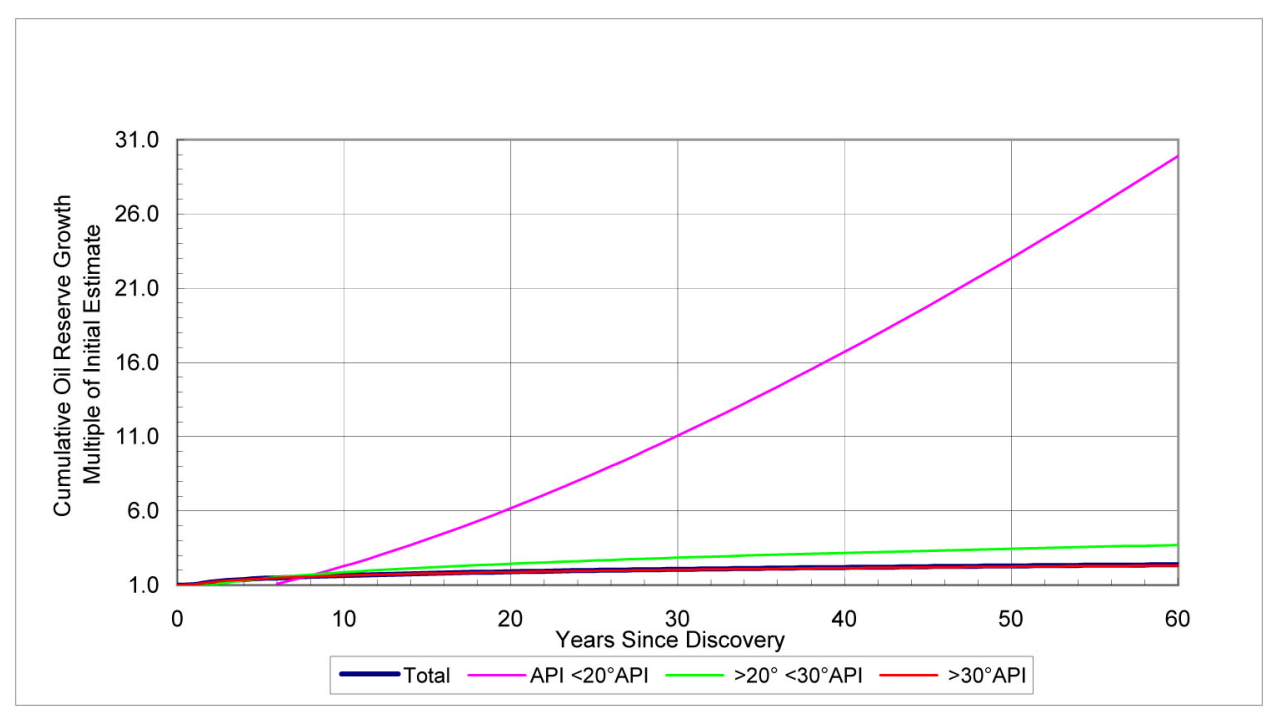

Figure 5. Relative reserve growths for Alberta pools with heavy oil (gravity $<20^{\circ} \mathrm{API}$ ), medium oil (gravity between $20^{\circ}$ and $30^{\circ} \mathrm{API}$ ) and light oil (gravity $>30$ " API). Heavy oil pools show significantly larger growth but make up only a small portion of the total recoverable oil. The bulk of the pools have light gravity oil, therefore the growth of those pools mirror the overall growth.

For studying reserve growth sensitivity to porosity, pools were also grouped into three categories - pools with porosity less than 10 percent, between 10 and 20 percent, and greater than 20 percent. The results shown in figure 6 clearly demonstrate that the pools with higher porosity did better in terms of reserve growth. 


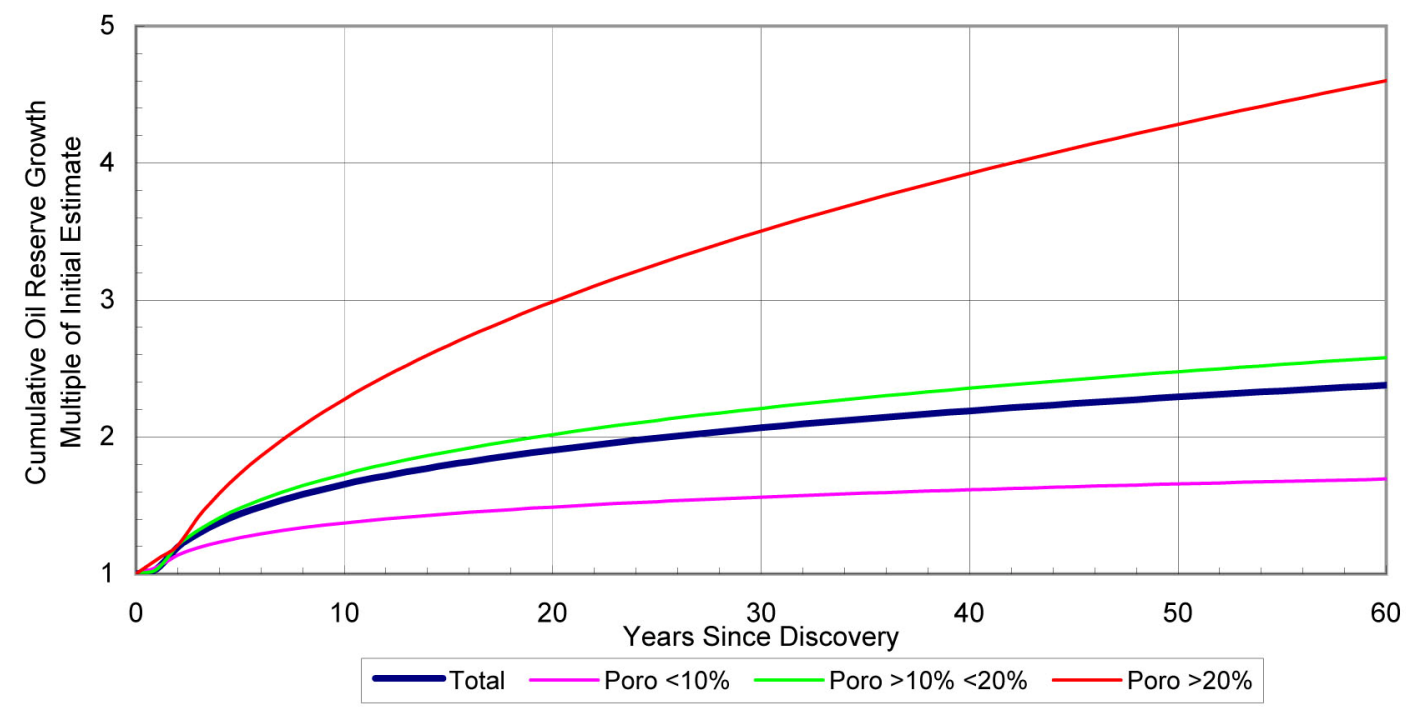

Figure 6. Reserve growth for Alberta oil pools with porosities less than $10 \%$, between 10 and $20 \%$, and greater than $20 \%$. Reserve growth appears to be highest in higher porosity pools.

Reserve growth over a 50-yr period was observed to be about 2.9-fold at the pool level (fig. 2) compared with about 5.0-fold at the field level (fig. 7).

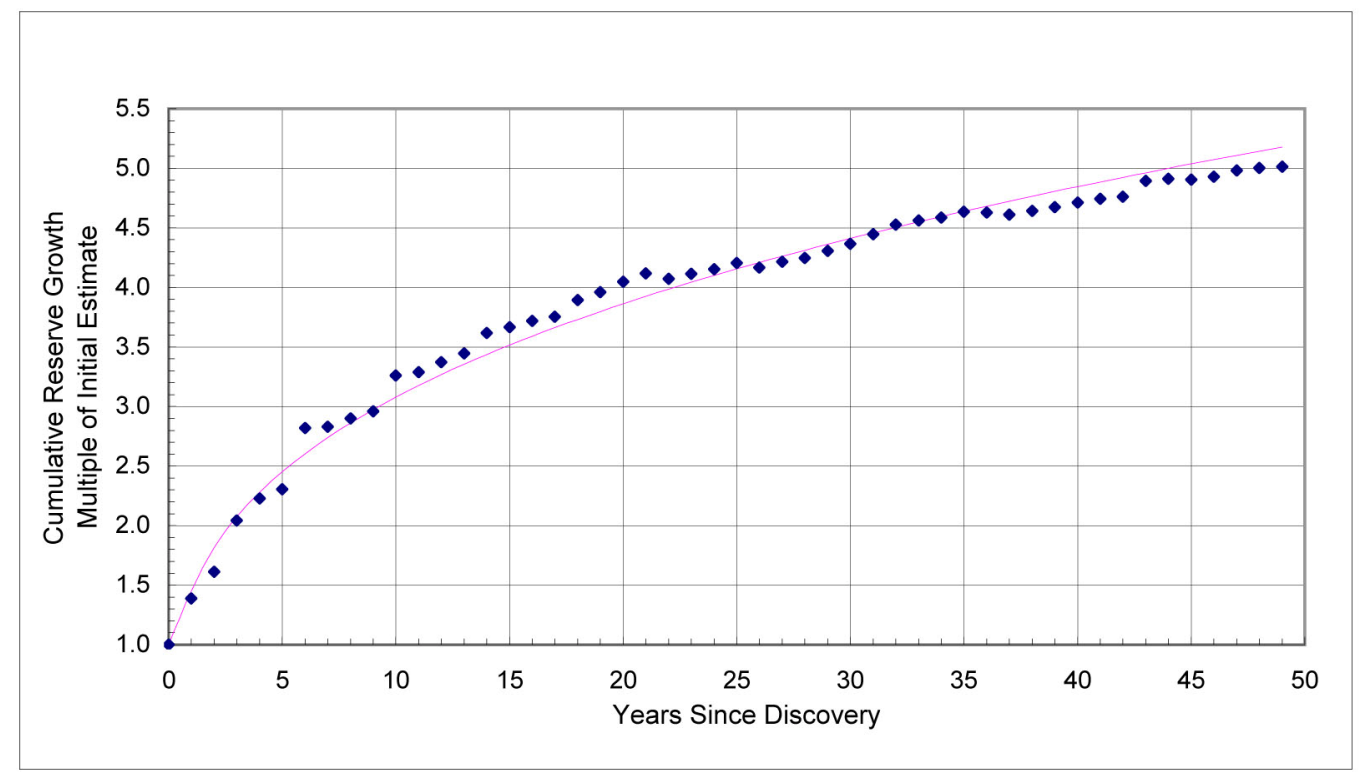

Figure 7. Cumulative reserve growth values for fields in Alberta Province plotted against field discovery years (blue diamonds). Data were regressed using Power function (pink curve), which is represented by the equation shown on the plot. 
Reserve growth values for some of the world's important petroleumproducing areas, such as Saskatchewan Province (Verma and Henry, 2004), West Siberian Basin (Verma and Ulmishek, 2003), Volga-Ural Basin (Verma, Ulmishek and Gilberstein, 2001), U.S. onshore fields (Verma, 2005), and U.S. Gulf of Mexico (Lore and others, 1996) are plotted in figure 8. From the plot, it can be seen that reserve growth in the Alberta oil pools is the lowest, although growth at the field level would compare well with that of the U.S. oil fields.

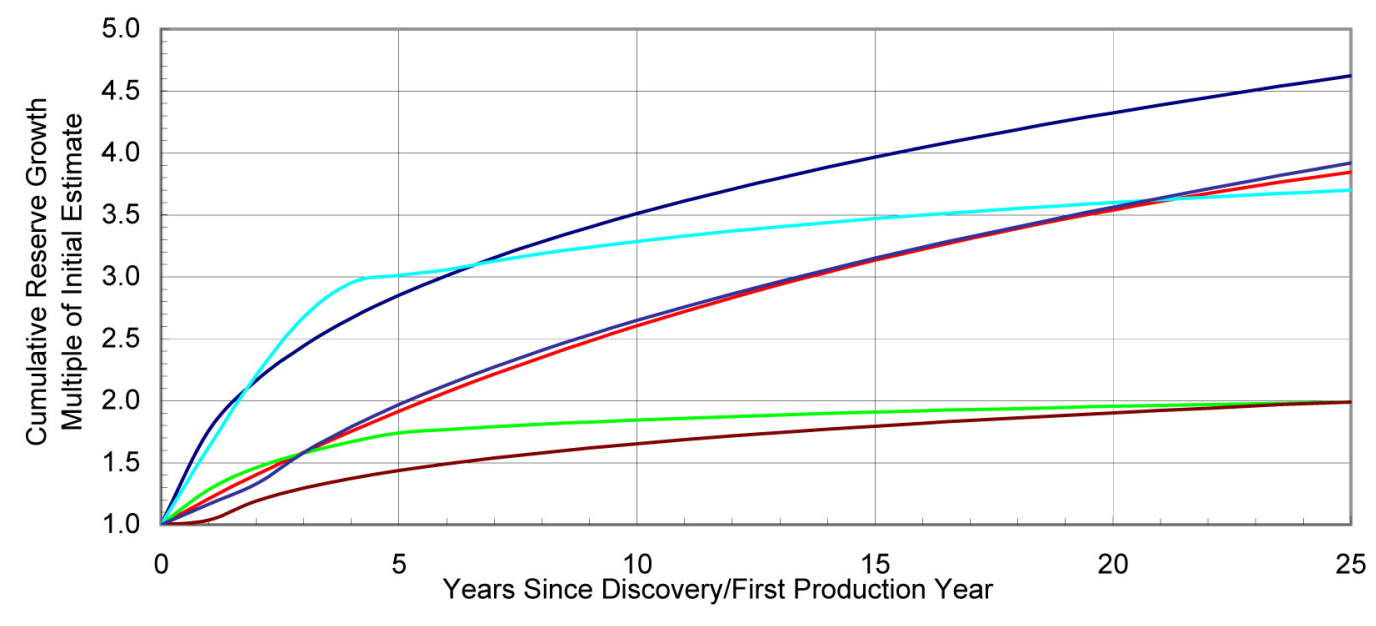

Figure 8. Relative reserve growth functions for some of the world's large petroleum-producing areas. Reserve growths of pools/fields are calculated with discovery (Disc) or the first production year (Prod) as the reference year. Reserve growth at the pool level for the Alberta Province is the lowest among those studied thus far.

\section{Conclusions}

The following general conclusions can be drawn from the study results.

1. Reserve growth in Alberta oil pools is the lowest of the regions studied. However, its growth at field level will fall in the same range as that of U.S. offshore (Gulf of Mexico) fields and Saskatchewan pools.

2. Larger pools ( $>125,000$ barrels), which make up about 99 percent of recoverable oil volume, show the most growth, whereas smaller pools show negative growth. 
3. Alberta's light oil pools ( $>30^{\circ}$ API) have the lowest growth (2-fold), but they make up the bulk of the recoverable oil volume; heavy oil pools $\left(<20^{\circ}\right.$ API) with lowest recoverable oil volumes show appreciably greater growth (30-fold).

4. Reserve growth increases with the increase in formation porosity.

\section{References Cited}

Lore, G.L. Brooke, J.P., Cooke, D.W., Klazynski, R.J., Olson, D.L., and Ross, K.M., 1996, Summary of the 1995 assessment of the conventionally recoverable hydrocarbon resources of the Gulf of Mexico and Atlantic Shelf: Minerals Management Services, OCS Report MMS 96-003, Appendix A.

Verma, M.K., Ulmishek, G.F., and Gilbershtein, A.P., 2001, Slower reserve growth rates observed in Volga-Ural Province, Russia: Oil and Gas Journal, v. 99, no. 9, p. 34-44.

Verma, M.K., and Ulmishek, G.F., 2003, Reserve growth in oil fields of West Siberian Basin, Russia: Natural Resources Research, v.12, no. 2, June, p. 105-119.

Verma, M.K., and Henry, M.E., 2004, Historical and potential reserve growth in oil and gas pools in Saskatchewan: Summary of Investigations, Miscellaneous Report 2004-4.1, Saskatchewan Industry and Resources, p. 1-19.

Verma, M.K., 2005, A new reserve model for United States oil and gas fields: Natural Resources Research, v.14, no. 2, June 2005, p. 77-89. 